\title{
STUDY OF GLENOID CAVITY OF HUMAN SCAPULA AND ITS CLINICAL
} IMPORTANCE

\author{
Ajay M. Parmar *1, Bhadresh Vaghela 2, Kanan P. Shah ${ }^{3}$, G C Agarwal ${ }^{4}$. \\ ${ }^{* 1}$ Assistant Professor , Department of Anatomy, PMCH, Udaipur, India. \\ ${ }^{2}$ Assistant professor, Anatomy Department, GMERS Medical Collage, Valsad, Gujarat, India. \\ ${ }^{3}$ Associate Professor, Department of Anatomy, Smt. N.H.L. MMC, Ahmedabad, India. \\ ${ }^{4}$ Professor\&Head, Department of Anatomy, PMCH, Udaipur, India.
}

\section{ABSTRACT}

Introduction: The morphology of the glenoid cavity is highly variable. It articulates with the head of the humerus at the glenohumeral joint. Shoulder joint is frequently dislocated so the knowledge of anatomic parameters and different shape of glenoid cavity are necessary for complete understanding of the mechanics of shoulder joint. The aim of the present study was to obtain the anthropometric data of the glenoid cavity of the scapula and to study the various shapes of the glenoid cavity which will help in management of shoulder pathology.

Materials and Methods: This study was done on 60 (30 right, 30 left) adult human scapula. Different parameter superior-inferior(SI), anterior-posterior diameter of the lower half(AP-1), anterior-posterior diameter of the upper half(AP-2) of glenoid cavity have been measured with the help of digital vernier calipers and glenoid cavity index was calculated. The shape of the glenoid cavity was classified as inverted comma shaped, pear shaped and oval shaped depending upon the presence or absence of a notch on the glenoid rim.

Results: The average SI diameter on right and the left sides were $37.31 \pm 2.91 \mathrm{~mm}$ and $37.46 \pm 2.92 \mathrm{~mm}$ respectively. The average AP-1 diameter of the right glenoid was $25.90 \pm 2.09 \mathrm{~mm}$ and that of the left was $25.70 \pm 2.32 \mathrm{~mm}$. The mean AP-2 diameter of the right glenoid was $17.89 \pm 1.52 \mathrm{~mm}$ and that of the left was $18.15 \pm 1.80 \mathrm{~mm}$. The mean GCl of the right glenoid was $69.54 \pm 4.22 \mathrm{~mm}$ and that of the left was $68.65 \pm 4.12 \mathrm{~mm}$.

Conclusion: All the parameters showed a very close value for the right and left side. The difference seen between the values of present study and that of other workers could be explained on the basis of ethnic and racial variations. This fact may be taken into consideration while performing shoulder arthroplasty and designing glenoid prostheses in rajasthan population. The current study also recorded a higher percentage of the glenoid notch $(>80 \%)$ in the anterior margin of the glenoid cavity. While evaluating defects and lesions of the glenoid, this fact could be useful. Thus a sound knowledge of various parameters of the glenoid cavity is important for the anatomists, anthropologists, orthopaedicians and prosthetists.

KEY WORDS: Scapula, Glenoid cavity, Glenoid notch, Glenohumeral joint.

Address for Correspondence: Dr. Ajay M. Parmar, Assistant professor, Department of Anatomy, PMCH, Udaipur, India. E-Mail: Drajay9118@gmail.com

\section{Access this Article online}

\begin{tabular}{c|c} 
Quick Response code & Web site: International Journal of Anatomy and Research \\
ISSN 2321-4287 \\
www.ijmhr.org/ijar.htm
\end{tabular}

Received: 02 June 2017

Peer Review: 03 June 2017

DOI: $10.16965 /$ ijar.2017.279

Revised: None
Accepted: $18 \mathrm{Jul} 2017$

Published (O): 31 Aug 2017

Published (P): 31 Aug 2017

\section{INTRODUCTION}

The scapula is a large, flat, triangular bone which lies on the posterolateral aspect of the chest wall, covering parts of the second to sev- 
enth ribs. The lateral angle, truncated and broad, bears the glenoid cavity which articulates with the head of the humerus at the glenohumeral joint. It is narrow above and wider below, provides a shallow, and limited, socket for the humeral head [1]. The morphology of the glenoid cavity is highly variable. The glenoid rim presents a notch in its upper and front part [2]. Due to presence of this glenoid notch, various shapes of glenoid cavity are found like pearshaped, oval or inverted comma shaped $[3,4]$. Shoulder joint is frequently dislocated inferiorly due to having less support in that region of the joint. During trauma, dislocation with fracture of glenoid are also common. During treatment repair of the labrum, reinforcing the capsule, rearrangement of anterior muscle and total shoulder replacement is also being used as treatment [5].

The knowledge of anatomic parameters and different shape of glenoid cavity are necessary for complete understanding of the mechanics of shoulder joint. Therefore, the present study was carried out which provides valuable anatomic parameters which would help the anatomists, orthopedicians, anthropologists and prosthetists.

The aim of the present study was to obtain the anthropometric data of the glenoid cavity of the scapula and to study the various shapes of the glenoid cavity relevant to rajasthan population which will help in better understanding and management of shoulder pathology.

\section{MATERIALS AND METHODS}

This study was done on 60 (30 right, 30 left) adult human scapula of unknown sex obtained from Department of Anatomy, Pacific Medical Collage, Udaipur.

Inclusion criteria- scapula included were dry, complete and showed normal anatomical features with clear intact glenoid cavity

Exclusion criteria- evidence of previous trauma, skeletal disorders, osteoarthritic changes

All the measurements were carried out with the help of vernier calipers and recorded in millimeters.

All the data were entered and analysed by the microsoft office excel 2010.

The following parameters of the glenoid cavity of scapula were studied.

Superior- Inferior Glenoid Diameter (SI): maximum distance from the inferior point on the glenoid margin to the most prominent point of the supra -glenoid tubercle (fig.1).

Anterior-Posterior Glenoid Diameter (AP-1): maximum breadth of the articular margin of the glenoid cavity perpendicular to the glenoid cavity height (fig.1)

Anterior-Posterior Glenoid Diameter (AP-2): represents the anterior-posterior diameter (breadth) of the top half of the glenoid cavity at the mid-point between the superior rim and the mid-equator(fig.1)

\section{Glenoid Cavity Index (GCI):}

$\mathrm{GCl}=\frac{\text { Antero-posterior glenoid diameter } 1 \times 100}{\text { Supero-inferior glenoid diameter }}$

Shape Of The Glenoid Cavity: The tracing of the shape of the glenoid cavity was taken on a white paper with the help of a lead pencil. on the basis of tracings drawn: Three types of glenoid were found inverted comma shaped, oval and pear shaped(fig.2).

Fig. 1: Schematic diagram showing various diameters of the glenoid cavity. A-B: Superior-Inferior diameter (SI), C-D: Anterior Posterior diameter-1 (AP-1), E-F: AnteriorPosterior diameter-2 (AP-2).

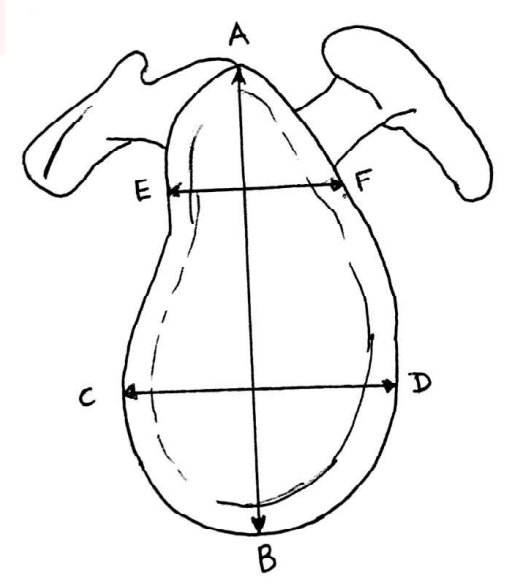

Fig. 2: Photograph showing various shapes of the glenoid cavity, A- Oval, B- Pear , C- Inverted comma.

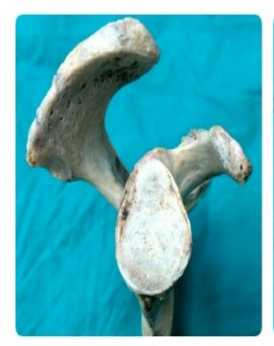

A

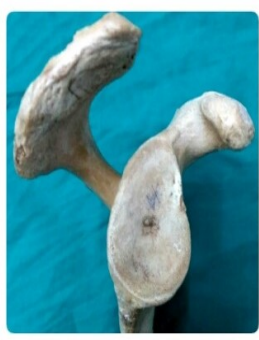

B

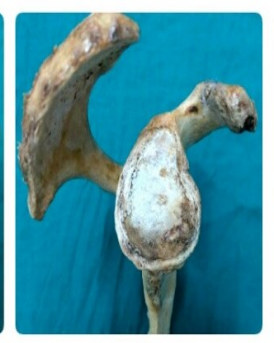

C 


\section{RESULTS}

Table 1 shows SI diameter of glenoid cavity on the right side varies from 30.94 to $41.69 \mathrm{~mm}$, with an average of $37.31 \pm 2.91 \mathrm{~mm}$ and on left side varies from 29.06 to $43.80 \mathrm{~mm}$, with an average of $37.46 \pm 2.92 \mathrm{~mm}$.

Table 1: SI diameter of right and left side glenoid cavity.

\begin{tabular}{|c|c|c|c|}
\hline Side & Range & Mean \pm SD & $\begin{array}{c}\text { Statistical } \\
\text { significance }\end{array}$ \\
\hline Right & 30.94 to $41.69 \mathrm{~mm}$ & $37.31 \pm 2.91 \mathrm{~mm}$ & $\mathrm{t}=0.20$ \\
Left & 29.06 to $43.80 \mathrm{~mm}$ & $37.46 \pm 2.92 \mathrm{~mm}$ & $\mathrm{P}=0.84$ \\
\hline
\end{tabular}

Table 2 shows AP1 diameter of glenoid cavity on the right side varies from 20.68 to $30.34 \mathrm{~mm}$, with an average of $25.90 \pm 2.09 \mathrm{~mm}$ and on left side varies from 19.94 to $30.60 \mathrm{~mm}$, with an average of $25.70 \pm 2.32 \mathrm{~mm}$.

Table 2: AP1diameter of right and left side glenoid cavity.

\begin{tabular}{|c|c|c|c|}
\hline Side & Range & Mean $\pm S D$ & $\begin{array}{c}\text { Statistical } \\
\text { significance }\end{array}$ \\
\hline Right & 20.68 to $30.34 \mathrm{~mm}$ & $25.90 \pm 2.09 \mathrm{~mm}$ & $\mathrm{t}=0.36$ \\
$\mathrm{Left}$ & 19.94 to $30.60 \mathrm{~mm}$ & $25.70 \pm 2.32 \mathrm{~mm}$ & $\mathrm{P}=0.71$ \\
\hline
\end{tabular}

Table 3 shows AP2 diameter of glenoid cavity on the right side varies from 14 to $22.39 \mathrm{~mm}$, with an average of $17.89 \pm 1.52 \mathrm{~mm}$ and on left side varies from 13.86 to $22.5 \mathrm{~mm}$, with an average of $18.15 \pm 1.80 \mathrm{~mm}$.

Table 3: AP2 diameter of right and left side glenoid cavity.

\begin{tabular}{|c|c|c|c|}
\hline Side & Range & Mean \pm SD & $\begin{array}{c}\text { Statistical } \\
\text { significance }\end{array}$ \\
\hline Right & 14 to $22.39 \mathrm{~mm}$ & $17.89 \pm 1.52 \mathrm{~mm}$ & $\mathrm{t}=0.61$ \\
$\mathrm{Left}$ & 13.86 to $22.5 \mathrm{~mm}$ & $18.15 \pm 1.80 \mathrm{~mm}$ & $\mathrm{P}=0.54$ \\
\hline
\end{tabular}

Table 4 shows different shapes of glenoid cavity. There was oval, pear and inverted comma shape of glenoid cavity found. On right side out of 30 scapula $6(20.00 \%)$ oval shaped, $16(53.34 \%)$ pear shaped, $8(26.66 \%)$ inverted comma shaped glenoid cavity found. On left side out of 30 scapula $5(16.66 \%)$ oval shaped, $14(46.67 \%)$ pear shaped, $11(36.30 \%)$ inverted comma shaped glenoid cavity found.

Table 4: Shapes of right and left side glenoid cavity.

\begin{tabular}{|c|c|c|c|c|}
\hline \multirow{2}{*}{ Shape of glenoid } & \multicolumn{2}{|c|}{ Right } & \multicolumn{2}{c|}{ Left } \\
\cline { 2 - 5 } & $\begin{array}{c}\text { No. of } \\
\text { bones }\end{array}$ & $\begin{array}{c}\text { Incidence } \\
\text { of shape }\end{array}$ & $\begin{array}{c}\text { No. of } \\
\text { bones }\end{array}$ & $\begin{array}{c}\text { Incidence } \\
\text { of shape }\end{array}$ \\
\hline Oval & 6 & $20.00 \%$ & 5 & $16.66 \%$ \\
\hline Pear & 16 & $53.34 \%$ & 14 & $46.67 \%$ \\
\hline Inverted comma & 8 & $26.66 \%$ & 11 & $36.30 \%$ \\
\hline
\end{tabular}

Int J Anat Res 2017, 5(3.2):4177-81. ISSN 2321-4287
Table 5 shows the glenoid cavity index, on the right side varies from 59.73 to $75.35 \mathrm{~mm}$, with an average of $69.54 \pm 4.22 \mathrm{~mm}$ and on left side varies from 59.15 to $75.03 \mathrm{~mm}$, with an average of $68.65 \pm 4.12 \mathrm{~mm}$.

Table 5: GC Index of right and left side glenoid cavity.

\begin{tabular}{|c|c|c|c|}
\hline Side & Range & Mean \pm SD & $\begin{array}{c}\text { Statistical } \\
\text { significance }\end{array}$ \\
\hline Right & 59.73 to $75.35 \mathrm{~mm}$ & $69.54 \pm 4.22 \mathrm{~mm}$ & $\mathrm{t}=0.82$ \\
\cline { 1 - 3 } Left & 59.15 to $75.03 \mathrm{~mm}$ & $68.65 \pm 4.12 \mathrm{~mm}$ & $\mathrm{P}=0.41$ \\
\hline
\end{tabular}

\section{DISCUSSION}

Many studies have been done by various workers on different races and groups of population about the morphometry of scapula and glenoid cavity in a variety of way like direct measurement on embalmed cadavers, direct measurement of dry scapulae, radiographic measurements of scapulae harvested from the cadavers and radiographic measurements in the living patients etc. The present study was performed on dry human scapulae. The comparison of data between present study and previous studies found several differences as well as similarities in the dimensions of the scapula and glenoid cavity (Table 6).

In the present study the average superior-inferior diameter of the right glenoid was $37.31 \pm 2.91$ $\mathrm{mm}$ and the average superior-inferior diameter of the left glenoid was $37.46 \pm 2.92 \mathrm{~mm}$. Von Schroeder et al [7], Coskun et al [10] and Karelse et al [11] reported the SI diameter to be $36 \pm 4 \mathrm{~mm}$, $36.3 \pm 3 \mathrm{~mm}$ and $35.9 \pm 3.6 \mathrm{~mm}$ respectively. All these values are lower than what was recorded in our study. Mamatha et al [12], Rajput et al [13] and Patil et al [14], measured the SI diameter of right and left side separately. The mean SI diameter of right side measured by these three authors was $33.67 \pm 2.82 \mathrm{~mm}, 34.76 \pm 3 \mathrm{~mm}$ and $35.2 \pm 3.0 \mathrm{~mm}$ respectively and of the left side was $33.92 \pm 2.87 \mathrm{~mm}, 34.43 \pm 3.21 \mathrm{~mm}$ and $34.7 \pm 2.8 \mathrm{~mm}$ respectively.

Frutos LR [8], Taser $F$ et al [9] measured the SI diameter of the male and female glenoid separately. The average SI diameter of male glenoid measured by these authors was $36.08 \pm 2.05 \mathrm{~mm}$ and $37.1 \pm 3.4 \mathrm{~mm}$ respectively. All these measurements are near to that reported in our present study. In our study the 
Ajay M. Parmar et al. STUDY OF GLENOID CAVITY OF HUMAN SCAPULA AND ITS CLINICAL IMPORTANCE.

Table 6: Comparison of different parameters of glenoid cavity by various authors.

\begin{tabular}{|c|c|c|c|c|c|}
\hline S. no. & Author & No of specimen & $\begin{array}{c}\text { Mean SI } \\
\text { diameter }(\mathrm{mm})\end{array}$ & $\begin{array}{c}\text { Mean AP1 } \\
\text { diameter }(\mathrm{mm})\end{array}$ & $\begin{array}{c}\text { Mean AP2 } \\
\text { diameter }(\mathrm{mm})\end{array}$ \\
\hline 1 & lannoti et al(6) (1992) & 140 & $39 \pm 3.5$ & $29 \pm 3.2$ & $23 \pm 2.7$ \\
\hline 2 & Von Schroeder et al(7) (2001) & 30 & $36 \pm 4$ & $28.6 \pm 3.3$ & \\
\hline 3 & Luis rios frutos(8) (2002) & $\begin{array}{c}\text { Male-65 } \\
\text { Female-38 }\end{array}$ & $\begin{array}{l}36.08 \pm 4 \\
31.17 \pm 1.7\end{array}$ & $\begin{array}{l}26.3 \pm 1.5 \\
22.31 \pm 1.4\end{array}$ & \\
\hline 4 & Taser F \& Basaloglu H (9) (2003) & $\begin{array}{c}\text { Male-13 } \\
\text { Female-39 }\end{array}$ & $\begin{array}{l}37.1 \pm 3.4 \\
34.1 \pm 2.9\end{array}$ & $\begin{array}{l}26.6 \pm 2.1 \\
25.0 \pm 2.7\end{array}$ & \\
\hline 5 & Coskun et al(10) (2006) & 90 & $36.3 \pm 3$ & $24.6 \pm 2.5$ & \\
\hline 6 & Karelse et al(11) (2007) & 40 & $35.9 \pm 3.6$ & $27.2 \pm 3.0$ & \\
\hline 7 & Mamatha et al(12) (2009) & $\begin{array}{l}\text { Right-98 } \\
\text { Left-104 }\end{array}$ & $\begin{array}{l}33.67 \pm 2.82 \\
33.92 \pm 2.87\end{array}$ & $\begin{array}{l}23.35 \pm 2.04 \\
23.02 \pm 2.30\end{array}$ & \\
\hline 8 & Rajput et al(13) (2012) & $\begin{array}{l}\text { Right-43 } \\
\text { Left-57 }\end{array}$ & $\begin{array}{c}34.76 \pm 3 \\
34.43 \pm 3.21\end{array}$ & $\begin{array}{c}23.31 \pm 3 \\
22.92 \pm 2.80\end{array}$ & \\
\hline 9 & Patil et al(14) (2014) & $\begin{array}{l}\text { Right:104 } \\
\text { Left: } 120\end{array}$ & $\begin{array}{l}33.68 \pm 4.32 \\
32.09 \pm 4.11\end{array}$ & $\begin{array}{l}23.29 \pm 2.34 \\
24.90 \pm 2.95\end{array}$ & $\begin{array}{l}15.74 \pm 1.75 \\
16.81 \pm 1.74\end{array}$ \\
\hline 10 & Present study(2017) & $\begin{array}{l}\text { Right-30 } \\
\text { Left-30 }\end{array}$ & $\begin{array}{l}37.31 \pm 2.91 \\
37.46 \pm 2.92\end{array}$ & $\begin{array}{l}25.90 \pm 2.09 \\
25.70 \pm 2.32\end{array}$ & $\begin{array}{l}17.89 \pm 1.52 \\
18.15 \pm 1.80\end{array}$ \\
\hline
\end{tabular}

sex of the scapulae was not known, therefore we could not measure them separately.

In the present study the average AP1 diameter of glenoid cavity on the right side was $25.90 \pm 2.09 \mathrm{~mm}$ and on left side was $25.70 \pm 2.32$ $\mathrm{mm}$. The combined average of both sides was $25.80 \pm 2.21 \mathrm{~mm}$. This was very higher to what was observed in the female glenoids studied by Churchill et al [4], Luis Rios Frutos [8]. Churchill et al [4], recorded the average AP-1 diameter to be $23.6 \pm 1.5 \mathrm{~mm}$ and Luis Rios Frutos [8] found it to be $22.31 \pm 1.49 \mathrm{~mm}$. The values recorded for the AP-1 diameter for the male glenoids were $27.8 \pm 1.6 \mathrm{~mm}$ by Churchill et al [4]. and $26.31 \pm$ $1.57 \mathrm{~mm}$ by Luis Rios Frutos [8]. All these values were very close to our combined average of both right and left sides, $25.80 \pm$ $2.21 \mathrm{~mm}$. The AP-1 diameter for female recorded by Taser F et al [9], which was $25.0 \pm 2.7 \mathrm{~mm}$ was quite close to what was recorded in the present study which was $25.80 \pm 2.21 \mathrm{~mm}$.

In the present study the average AP2 diameter of glenoid cavity on the right side was $17.89 \pm$ $1.52 \mathrm{~mm}$ and on left side was $18.15 \pm 1.80 \mathrm{~mm}$. The combined average of both sides was $18.02 \pm$ $1.66 \mathrm{~mm}$. This was much lower than what was observed by lannotti et al [6], which was $23 \pm$ $2.7 \mathrm{~mm}$. Average AP2 diameter of present study found very close to what observed in study by Patil et al [14], which were $15.74 \pm 1.75 \mathrm{~mm}$ on right side and $16.81 \pm 1.74$ on left side.
In the present study, $20 \%$ oval, 53.34\% pear, $26.66 \%$ inverted comma shaped glenoid cavity found on right scapula. $16.66 \%$ oval, $46.67 \%$ pear, $36.30 \%$ inverted comma shaped glenoid cavity found on left scapula. Mamatha et al [12] reported that on the right side $34 \%$ glenoid cavities were inverted comma shaped, $46 \%$ pear shaped and $20 \%$ oval shaped and on the left side they were $33 \%, 43 \%$ and $24 \%$ respectively. Rajput et al [13] recorded the incidence of inverted comma shaped, pear shaped and oval shaped as 35\%, $49 \%$ and $16 \%$ respectively on the right side and $39 \%, 46 \%$ and $15 \%$ respectively on the left side.

In the present study, oval glenoids were only of $20 \%$ on the right side and $16.66 \%$ on the left side. As compared to Mamatha et al [12] who found it to be $20 \%$ on the right side and $24 \%$ on the left side. Prescher and Kulmpen [3] observed that $45 \%$ of the glenoids were oval shaped Coskun $\mathrm{N}$ et al [10] studied 90 scapulae and found that, in $72 \%$ of the specimens, the glenoid notches of the scapulae were absent or oval shaped, whereas in $28 \%$ the notch was well expressed and the glenoid cavity was pear shaped. These findings were higher than that of the present study.

The percentage of glenoids with both indistinct and distinct notch was $80 \%$ on the right side and $83 \%$ on the left side. Mamatha et al [12] had found it to be $80 \%$ on the right side and $76 \%$ on 
the left side. Prescher and Klumpen [3] had observed it to be $55 \%$ which was much lesser than in the present study.

In the present study, mean glenoid cavity index $(\mathrm{GCl})$ on the right side was $69.54 \pm 4.22 \mathrm{~mm}$ and on left side $68.65 \pm 4.12 \mathrm{~mm}$. The combined average of both sides was $69.09 \pm 4.16 \mathrm{~mm}$. Polguj $\mathrm{M}$ et al [15] noted the combined $\mathrm{GCl}$ to be $72.35 \pm 5.55$, which was higher than the present study. The mean cavity index of $70.37 \pm 4.08 \%$ on right side while $68.59 \pm 4.36 \%$ on left side recorded by Dhindsa et al [16] were found very close to present study.

\section{CONCLUSION}

The knowledge of the variation in the different shape and dimensions of the glenoid cavity are important in better understanding of the shoulder pathology and in designing and fitting of glenoid components for total shoulder arthroplasty.

The mean values of SI, AP1, AP2 diameter on both right and left side are almost similar. The above data on the different shape and dimensions of the glenoid cavity may not only help the orthopedicians and prosthetists but also helpful to anthropologists for studying about the evolution of the bipedal gait in human being. Since the present study had taken a smaller number of scapula and were not of the same skeleton, further cadaveric, radiological and clinical studies are indicated.

\section{ABBREVIATIONS}

\section{SI - Superior-Inferior Diameter}

AP-1 - Anterior-Posterior Diameter Of The Lower Half

AP-2 - Anterior-Posterior Diameter Of The Upper Half

GCI - Glenoid Cavity Index

mm - millimetre

SD - standard deviation

\section{Conflicts of Interests: None}

\section{REFERENCES}

[1]. Standring S., Gray's Anatomy- Anatomical basis of clinical practice, 39th ed., p. 819-820.

[2]. Breathnach AS. Frazer's Anatomy of the Human Skeleton.6th ed. London: J and A Churchill Ltd; 1965;63-70.

[3]. Prescher A, Klumpen T. The glenoid notch and its relation to the shape of the glenoid cavity of the scapula. J Anat 1997;190(3):457-60.

[4]. Churchill RS, Brems JJ, Kotschi H. Glenoid size, inclination, and version: An anatomic study. J Shoulder Elbow Surg 2001;10(4):327-32.

[5]. Chummy S Sinnatamby. Last's anatomy, Regional and applied. Eleventh edition. Churchill livingstone (London).2006:50-52.

[6]. Iannotti JP, Gabriel JP, Schneck SL, Evans BG, Misra $S$. The normal glenohumeral relationships. An anatomical study of one hundred and forty shoulders. J Bone Joint Surg Am 1992;74:491-500.

[7]. Von Schroeder HP, Kuiper SD, Botte MJ. Osseous anatomy of the scapula. Clinical orthopedics and related research, 2001;383:131-139.

[8]. Frutos LR. Determination of sex from the clavicle and scapula in a Guatemalan contemporary rural indigenous population. Am J Forensic Med and Pathol. 2002;23:284-8.

[9]. Taser F, Basaloglu H. Morphometric Dimensions of the Scapula. Ege Journal of Medicine 2003;42(2):7380.

[10]. Coskun N, Karaali K, Cevikol C, Demirel BM, Sindel M. Anatomical basics and variations of the scapula in Turkish adults. Saudi Med J 2006;27(9):1320-5.

[11]. Karelse A, Kegels L, De Wilde L. The pillars of the scapula. Clin Anat 2007;20:392-9.

[12]. Mamatha T, Pai SR, Murlimanju BV, Kalthur SG, Pai MM, Kumar B. Morphometry of Glenoid Cavity. Online J Health Allied Scs 2011;10(3):1-4.

[13]. Rajput HB, Vyas KK, Shroff BD. A Study of Morphological Patterns of Glenoid Cavity of Scapula. Natl J Med Res 2012;2(4):504-7.

[14]. Patil GV, Kolagi SI, Ramdurg U. Morphometrical study of scapular glenoid cavities. Global Journal of Medical Research: Orthopedics and Musculoskeletal system. 2014;14(2):9-14.

[15]. Polguj M, Jedrzejewski KS, Podgorski M, Topol M. Correlation between morphometry of the suprascapular notch and anthropometric measurements of the scapula. Folia Morphol 2011;70(2);109-15.

[16]. Dhindsa GS, Singh Z. A study of morphology of glenoid cavity. Journal of Evolution of Medical and Dental Sciences. 2014;3:7036-43.

How to cite this article:

Ajay M. Parmar, Bhadresh Vaghela, Kanan P. Shah, G C Agarwal. STUDY OF GLENOID CAVITY OF HUMAN SCAPULA AND ITS CLINICAL IMPORTANCE. Int J Anat Res 2017;5(3.2):4177-4181. DOI: 10.16965/ijar.2017.279 